\title{
Treatment of Motor Symptoms in Idiopathic Parkinson's Disease
}

\author{
Elif GÖKÇAL, Gülsen BABACAN YILDIZ
}

Department of Neurology, Bezmialem Vakif University Faculty of Medicine, Istanbul, Turkey

\begin{abstract}
Idiopathic Parkinson's disease is one of the most common neurodegenerative disorders. Idiopathic Parkinson's disease continues to be a progressive disorder leading to severe disability caused by motor and non-motor symptoms. To date, there have been no disease-modifying or neuroprotective interventions that could stop or slow down disease progression. Treatment of motor symptoms, such as tremor, rigidity, and bradykinesia, is primarily focused on correcting dopamine deficiency. There are some medications that do not directly affect the dopaminergic system. Some invasive interventions are also available. Treatment options should be specified according to age, disease stage, functional status, and concurrent diseases of the patients. Non-motor symptoms, such as sleep disturbances and neuropsychiatric symptoms, should also be properly diagnosed and treated. This review focuses on treatment strategies for the motor symptoms of idiopathic Parkinson's disease.
\end{abstract}

Keywords: Idiopathic parkinson's disease, treatment, motor symptoms, review

\section{Introduction}

Idiopathic Parkinson's disease (IPD) is the second most common neurodegenerative disease after Alzheimer's disease, and its prevalence increases with age (1). A progressive decrease of dopaminergic neurons in the substantia nigra pars compacta and the accumulation of intranuclear alpha-synuclein inclusions (Lewy bodies) in the surviving neurons constitute the pathological basis of IPD (2). Because cholinergic, noradrenergic, and serotonergic innervation are affected in IPD, nonmotor symptoms also occur in addition to bradykinesia, resting tremors, and rigidity, which are the classical triad of IPD clinical symptoms (3).

Currently, neuroprotective or disease-modifying treatment does not exist for the IPD therapy (4), and almost all existing treatment options concentrated on the motor symptoms and aimed at increasing dopamine levels by reducing dopamine destruction or stimulating dopamine receptors or agents acting as dopamine precursors. Other treatment options involve medications not affecting the dopaminergic system and surgical intervention (Table 1). The age, predominant clinical symptoms, functional status, and associated co-morbidities of the patient are important in the treatment choice. Moreover, non-motor symptoms, such as neuropsychiatric symptoms, cognitive impairment, and sleep disorders, should be evaluated and considered in treatment protocols (5).

The treatment options currently used for IPD motor symptoms are discussed in this study.

\section{Dopaminergic Treatments}

\section{Monoamine oxidase type B inhibitors}

Selegiline and rasagiline reduces the destruction of dopamine by inhibiting the monoamine oxidase type B (MAO-B) isoenzyme (6). Although there are studies reporting the disease-modifying effect of rasagiline, this effect has not been supported in subsequent studies $(7,8)$. Rasagiline has been found to be more helpful with mild motor symptoms in early diagnosed patients before initiating more potent treatment such as dopamine agonists or levodopa (9), although rasagiline can also be used in advanced-stage patients in the additional treatment of levodopa and/or dopamine agonists. It was reported that rasagiline add-on therapy in patients taking levodopa decreases the off time (10).

MAO-B inhibitors are generally well tolerated. Unlike selegiline, rasagiline is not metabolized to amphetamine and methamphetamine, and this makes it safer in terms of side effects. Although rasagiline metabolism is different, it is said that 


\section{Table 1. Treatment choices for IPD motor symptoms}

1) Dopaminergic treatments

a) Monaamine oxidase type $\mathrm{B}$ (MAO-B) inhibitors

- Selegiline

- Rasagiline

b) Catechol-O-methyltransferase (COMT) inhibitors

- Tolcapone

- Entacapone

c) Dopamine receptor agonists (dopa agonists)

- Ergot derivative agonists (cabergoline, lisuride, pergolide, and bromocriptine)

- Non-ergot derivative agonists (Apomorphine, piribedil, pramipexole, ropinirole, and rotigotine)

d) Levodopa

- Levodopa+benserazide (standard/controlled released)

- Levodopa+carbidopa

- Levodopa+cardidopa+entecapone

- Levodopa+cardidopa duodenal gel

2) Non-dopaminergic treatments

- Amantadine

- Anticholinergic drugs (biperiden, benztropine, bornaprine, orphenadrine, procyclidine, and trihexyphenidyl)

3) Surgical treatment

- Lesion-based radiofrequency applications (thalamotomy and pallidotomy)

- Neurostimulation applications [deep brain stimulation (DBS)].

both MAO-B inhibitors, particularly when used with antidepressants, such as SSRI, may cause a clinical picture similar to a serotonin syndrome (11). However, it was reported in a recent multicenter retrospective study that its use with antidepressants is reliable (12). Nevertheless, providing sufficient warning to patients and keeping the dose of antidepressants as low as possible constitute a good clinical approach.

\section{Catechol-O-methyltransferase inhibitors}

Tolcapone and entacapone, which inhibit the enzyme causing peripheral destruction of levodopa, increases the passage of levodopa to the central nervous system. Because of this mechanism of action, Catechol-O-methyltransferase (COMT) inhibitors should be used in patients receiving levodopa therapy. Tolcapone as a single preparation is rarely used because of its severe liver toxicity. Entacapone is used both as a single preparation and in combination with levodopa and carbidopa. It was demonstrated that entacapone has a similar effect to rasagiline in terms of reducing the off times (13). In a study where triple combination therapy containing enta- it was observed that contrary to expectations, the combination therapy caused more dyskinesia in a shorter time (14). In clinical practice, this result, particularly in early stage patients, restricted the preference of triple combination therapy to the standard levodopa preparations. In advanced-stage patients, it is preferable to obtain a more stable levodopa concentration and to reduce the off times.

COMT inhibitors may cause dopaminergic side effects because they increase the bioavailability of levodopa. Nausea, cardiovascular, and neuropsychiatric side effects are among the dopaminergic side effects, whereas diarrhea and changes in the color of urine are the most common non-dopaminergic side effects (15).

\section{Dopamine receptor agonists}

Dopamine agonists (DAs) take effect by directly stimulating postsynaptic dopamine receptors. DAs are divided into two classes, namely ergot and non-ergot. Ergot derivative agonists (cabergoline, lisuride, pergolide, and bromocriptine) are currently not preferred because of the risks of valvular heart disease and pulmonary fibrosis. Apomorphine, which is a non-ergot derivative DA, is subcutaneously used, whereas piribedil, pramipexole, and ropinirole are orally used. Rotigotine, which was the first DA used in transdermal delivery, is currently in the licensing stage. The influence of DAs on the motor symptoms of IPD is greater than that of MAO-B inhibitors but lower than that of levodopa (3). Motor complications, particularly dyskinesias seen with levodopa are rarely observed in DAs $(16,17)$. Therefore, in IPD treatment, DAs are recommended, particularly in young patients, as the first choice, with the aim being to delay use of levodopa. However, with the progression of the disease and an increase in motor symptoms, the adequacy of DAs alone decreases over time $(16,18,19)$. In addition to the use of DAs in the early stages, there are studies reporting that pramipexole, ropinirole, and continuous subcutaneous apomorphine infusion reduce the off times in advanced-stage IPD patients receiving levodopa therapy (20). However, this add-on therapy may cause dyskinesia or could increase the existing dyskinesia. In clinical practice, when DAs are administered to patients with dyskinesia, reducing the levodopa dose is a correct approach (21). Long-acting forms of pramipexole and ropinirole are also reported to have similar efficacy and safety with this indication $(22,23)$. A single daily use dose of this preparation offers a significant advantage in terms of adherence to the treatment (24).

Apomorphine that is subcutaneously used is the strongest DA that acts very quickly. The intermittent subcutaneous injection of apomorphine is useful for the acute treatment of the off periods; furthermore, the long-term use of this therapy has been found to be safe $(25,26)$. Continuous subcutaneous infusion, which is another usage form of apomorphine, is useful in advanced-stage IPD patients with more motor fluctuations and unpredictable off periods (27). Although peripheral side effects, such as nausea and hypotension, restrict the use of 
apomorphine, it has become more commonly used with the development of application systems and drug usage against the side effects in recent years (28).

While the effect of all oral form of DAs on the motor symptoms is similar, the positive effect of pramipexole treatment, particularly on tremors, has been reported (29). There are also many studies reporting positive results of pramipexole on depression associated with IPD (30). Furthermore, it was demonstrated that pramipexole also has positive impacts on mood and motivational symptoms in Parkinson's patients without major depression (31).

The acute side effects of DAs are nausea, vomiting, and orthostatic hypotension. These side effects are observed at the beginning of therapy but usually decrease as tolerance develops. Although they cause fewer motor complications in comparison with levodopa, DAs cause some dopaminergic side effects more often than levodopa treatment (32). These side effects are hallucinations, excessive sleepiness during the day, sudden sleep attacks, and impulse control disorders. Because of these cognitive and psychiatric side effects, particularly in elderly patients who previously had cognitive impairment, the use of DAs should be avoided. Another complication of DAs, the cause of which is unknown, is edema in the ankle or leg.

\section{Levodopa}

Levodopa, which has been the most effective treatment for IPD for nearly 50 years, is the antiparkinsonian drug with the most powerful symptomatic effect $(3,15)$. Levodopa is a dopamine precursor and is converted into dopamine by dopaminergic nerve endings both in the central and peripheral nervous systems. Because dopamine cannot pass the blood-brain barrier when directly administered, it is given as levodopa (L-3,4-dihydroxy-phenylalanine), which is the precursor. However, when levodopa is orally administered alone, it is decarboxylated by dopa decarboxylase enzyme and converted to dopamine before passing the blood-brain barrier. Therefore, to prevent the peripheral conversion of levodopa to dopamine, it should be used in combination with benserazide or carbidopa, which are dopa decarboxylase inhibitors (33).

In our country, levodopa is found in the form of levodopa+benserazide, controlled-releaselevodopa+benserazide, levodopa+carbidopa, and levodopa+carbidopa+entacapone oral tablets and as levodopa intestinal gel. Because of the severe reduction in the intestinal absorption when taken with meals, oral levodopa preparations are always required to be taken on an empty stomach. In clinical practice, oral levodopa therapy is initiated with an initial dose of $50 \mathrm{mg}$ three times a day and by slowly escalating the dose until the target dose of $100 \mathrm{mg}$ three times a day is reached. Although when levodopa is used with decarboxylase inhibitors, it has a short half-life of $90 \mathrm{~min}$, and thus is required to be administered four times a day; there are no studies comparing the long-term benefits of these two dose ranges (3). In addition, because the use of four times a day makes adherence of the patient to the treatment more difficult, it is less preferred in clinical practice. A controlled-release dosage form of levodopa aims to reduce the dose frequency by extending the effect of a single dose, but it does not have superiority to standard levodopa in terms of the risk of motor complications (15). These preparations are usually administered to patients experiencing freezing at night and in the morning hours before going to bed for the continuation of the activity. It was observed that the preparation containing entacapone, shortened the development time of dyskinesia compared with standard levodopa preparations (14).

Depending on the temporal changes in the receptor levels, with the delay and/or variability of gastric emptying in advanced-stage patients, oral treatment causing abnormal pulsatile dopaminergic stimulation is considered to be responsible for motor complications. This situation leads to the necessity of applying continuous stimulation of the striatal dopaminergic neurons through dopaminergic stimulation $(34,35)$. The levodopa+carbidopa duodenal gel that was licensed and became available in our country for use with advanced-stage patients aims to deliver more constant plasma concentrations of levodopa, bypassing the gastrointestinal tract, and it is an effective treatment method reducing the off times, while not increasing dyskinesias (36). The duodenal tube inserted through the percutaneous endoscopic tube is usually accompanied by a pump hanging over the shoulder.

Although side effects of levodopa, such as nausea, vomiting, orthostatic hypotension, confusion, and sleep disorders, are encountered less in comparison to DAs, it can be disruptive in the therapy of some patients. An abrupt cessation of treatment in patients receiving long-term and high-dose levodopa may cause a clinical picture similar to neuroleptic malignant syndrome (NMS). NMS, with a clinical picture of confusion, muscle rigidity, fever, an increase in muscle enzymes, and a high mortality rate, is an urgent clinical case that should be diagnosed and treated early (33).

Though levodopa is the most effective treatment in PD patients, the most important factors restricting its use are motor fluctuations occurring with long-term treatment and motor complications such as dyskinesia. These complications are seen in approximately $75 \%-80 \%$ of patients using levodopa treatment for 5-10 years and particularly in early onset cases. These patients alternate between on-times with severe dyskinesia periods when they benefit from levodopa and the off times with severe motor dysfunction when they do not benefit from it. As the disease progresses, while controlling motor symptoms, the dose adjustment of levodopa able to prevent dyskinesia becomes harder (37). Levodopa delaying therapies should be considered first in patients, particularly in early ages, with mild motor symptoms, in order to prevent their coming to this stage. However, in some cases where the motor symptoms cause significant disability or where other 
treatment options cannot be used because of the side effects, levodopa may be unavoidable in the early ages as well.

\section{Other Treatment Options}

\section{Amantadine}

Though amantadine was first developed as an antiviral agent, it has taken been used in the therapy of dyskinesia over the years (38). Although the antiglutaminergic, anticholinergic, and dopaminergic effect mechanisms are not clearly understood, amantadine is believed to reduce dyskinesias by reducing glutaminergic cortical inputs to the striatal neurons (39). Common side effects include a dry mouth, dizziness, blurred vision, and insomnia. In addition, edema in the ankle or leg and livedo reticularis can be seen in some cases. It may also cause neuropsychiatric disorders, such as confusion and hallucinations, particularly in patients using high doses and in those who previously have had cognitive impairment (33).

\section{Anticholinergics}

Anticholinergic drugs (biperiden, benztropine, bornaprine, orphenadrine, procyclidine, and trihexyphenidyl) increase the activity of striatal acetylcholine by acting on muscarinic receptors; furthermore, they inhibit dopamine intake in the central dopaminergic neurons but at a poor rate. Though the most common side effects are dry mouth, nausea, blurred vision, and constipation, the most important side effect restricting usage, particularly in the elderly, is the deterioration of mental functioning (40).

\section{Surgical treatment}

In surgical treatment for Parkinson's symptoms, two types of stereotactic methods are used: lesion-based radiofrequency applications, namely thalamotomy or pallidotomy and neurostimulation applications, also known as deep brain stimulation (DBS). Surgical treatment options are not applied in elderly patients and patients with dementia. Thalamotomy is used in patients with resistant tremors to medical treatment; while, pallidotomy is used in patients with distinctive dyskinesias. However, in recent years, DBS as a neurostimulation method for subthalamic nucleus (STN) has become the most commonly used method because it is both reversible, pushing the lesion-based applications into the background due to its effectiveness in addressing motor functions (21). In a study evaluating patients who underwent STN-DBS for PD with 10 years of follow-up, it was observed that significant improvements were provided in motor functions, such as tremors and bradykinesia, as well as in motor complications, such as dyskinesia, and motor fluctuations, though the effectiveness decreases over time (41).

Peer-review: Externally peer-reviewed.

Author Contributions: Concept - G.B., E.G.; Design - G.B., E.G.; Supervision - G.B., E.G.; Data Collection and/or Processing - G.B., E.G.; Analysis and/or Interpretation - G.B., E.G.; Literature Review - G.B., E.G.; Writer - G.B., E.G.; Critical Review - G.B., E.G.

Conflict of Interest: The authors declared no conflict of interest.

Financial Disclosure: The authors declared that this study has received no financial support.

\section{References}

1. Pringsheim T, Jette N, Frolkis A, Steeves TD. The prevalence of Parkinson's disease: a systematic review and meta-analysis. Mov Disord 2014; 29: 1583-90. [CrossRef]

2. Takahashi H, Wakabayashi K. The cellular pathology of Parkinson's disease. Neuropathology 2001; 21: 315-22. [CrossRef]

3. Sprenger F, Poewe W. Management of motor and non-motor symptoms in Parkinson's disease. CNS Drugs 2013; 27: 259-72. [CrossRef]

4. AlDakheel A, Kalia LV, Lang AE. Pathogenesis-targeted, diseasemodifying therapies in Parkinson disease. Neurotherapeutics 2014; 11: 6-23. [CrossRef]

5. Chaudhuri KR, Odin P, Antonini A, Martinez-Martin P. Parkinson's disease: the non-motor issues. Parkinsonism Relat Disord 2011; 17: 717-23. [CrossRef]

6. Chen JJ, Swope DM. Clinical pharmacology of rasagiline: a novel, second-generation propargylamine for the treatment of Parkinson disease. J Clin Pharmacol 2005; 45: 878-94. [CrossRef]

7. Olanow CW, Rascol O, Hauser R, Feigin PD, Jankovic J, Lang A, et al. A double-blind, delayed-start trial of rasagiline in Parkinson's disease. N Engl J Med 2009; 361: 1268-78. [CrossRef]

8. Connolly BS, Lang AE. Pharmacological treatment of Parkinson disease: a review. JAMA 2014; 311: 1670-83. [CrossRef]

9. Parkinson Study Group. A controlled trial of rasagiline in early Parkinson disease: the TEMPO Study. Arch Neurol 2002; 59: $1937-$ 43. [CrossRef]

10. Parkinson Study Group. A randomized placebo-controlled trial of rasagiline in levodopa-treated patients with Parkinson disease and motor fluctuations: the PRESTO study. Arch Neurol 2005; 62: 241-8. [CrossRef]

11. Chen JJ, Swope DM, Dashtipour K. Comprehensive review of rasagiline, a second-generation monoamine oxidase inhibitor, for the treatment of Parkinson's disease. Clin Ther 2007; 29: 1825-49. [CrossRef]

12. Panisset M, Chen JJ, Rhyee SH, Conner J, Mathena J, STACCATO study investigators. Serotonin toxicity association with concomitant antidepressants and rasagiline treatment: retrospective study (STACCATO). Pharmacotherapy 2014; 34: 1250-8. [CrossRef]

13. Rascol O, Brooks DJ, Melamed E, Oertel W, Poewe W, Stocchi $\mathrm{F}$, et al. Rasagiline as an adjunct to levodopa in patients with Parkinson's disease and motor fluctuations (LARGO, Lasting effect in Adjunct therapy with Rasagiline Given Once daily, study): a randomised, double-blind, parallel-group trial. Lancet 2005; 365: 947-54. [CrossRef]

14. Stocchi F, Rascol O, Kieburtz K, Poewe W, Jankovic J, Tolosa E, et al. Initiating levodopa/carbidopa therapy with and without entacapone in early Parkinson disease: the STRIDE-PD study. Ann Neurol 2010; 68: 18-27. [CrossRef]

15. Horstink M, Tolosa E, Bonuccelli U, Deuschl G, Friedman A, Kanovsky P, et al. Review of the therapeutic management of Parkinson's disease. Report of a joint task force of the European Federation of Neurological Societies and the Movement Disorder Society-European Section. Part I: early (uncomplicated) Parkinson's disease. Eur J Neurol 2006; 13: 1170-85. [CrossRef] 
16. Hauser RA, Rascol O, Korczyn AD, Jon Stoessl A, Watts RL, Poewe W, et al. Ten-year follow-up of Parkinson's disease patients randomized to initial therapy with ropinirole or levodopa. Mov Disord 2007; 22: 2409-17. [CrossRef]

17. Rascol O, Brooks DJ, Korczyn AD, De Deyn PP, Clarke CE, Lang AE. A five-year study of the incidence of dyskinesia in patients with early Parkinson's disease who were treated with ropinirole or levodopa. N Engl J Med 2000; 342: 1484-91. [CrossRef]

18. Katzenschlager R, Head J, Schrag A, Ben-Shlomo Y, Evans A, Lees AJ, et al. Fourteen-year final report of the randomized PDRG-UK trial comparing three initial treatments in PD. Neurology 2008; 71: 474-80. [CrossRef]

19. Parkinson Study Group CCI. Long-term effect of initiating pramipexole vs levodopa in early Parkinson disease. Arch Neurol 2009; 66: 563-70. [CrossRef]

20. Pahwa R, Factor SA, Lyons KE, Ondo WG, Gronseth G, Bronte-Stewart $\mathrm{H}$, et al. Practice Parameter: treatment of Parkinson disease with motor fluctuations and dyskinesia (an evidence-based review): report of the Quality Standards Subcommittee of the American Academy of Neurology. Neurology 2006; 66: 983-95. [CrossRef]

21. Horstink M, Tolosa E, Bonuccelli U, Deuschl G, Friedman A, Kanovsky P, et al. Review of the therapeutic management of Parkinson's disease. Report of a joint task force of the European Federation of Neurological Societies (EFNS) and the Movement Disorder Society-European Section (MDS-ES). Part II: late (complicated) Parkinson's disease. Eur J Neurol 2006; 13: 1186-202. [CrossRef]

22. Schapira AH, Barone P, Hauser RA, Mizuno Y, Rascol O, Busse M, et al. Extended-release pramipexole in advanced Parkinson disease: a randomized controlled trial. Neurology 2011; 77: 767-74. [CrossRef]

23. Stocchi F, Giorgi L, Hunter B, Schapira AH. Prepared: Comparison of prolonged and immediate release ropinirole in advanced Parkinson's disease. Mov Disord 2011; 26: 1259-65. [CrossRef]

24. Grosset D. Dopamine agonists and therapy compliance. Neurol Sci 2008; 29 (Suppl 5) :S375-6. [CrossRef]

25. Dewey RB Jr, Hutton JT, LeWitt PA, Factor SA. A randomized, double-blind, placebo-controlled trial of subcutaneously injected apomorphine for parkinsonian off-state events. Arch Neurol 2001; 58: 1385-92. [CrossRef]

26. Pfeiffer RF, Gutmann L, Hull KL Jr, Bottini PB, Sherry JH, Investigators APOS. Continued efficacy and safety of subcutaneous apomorphine in patients with advanced Parkinson's disease. Parkinsonism Relat Disord 2007; 13: 93-100. [CrossRef]
27. Garcia Ruiz PJ, Sesar Ignacio A, Ares Pensado B, Castro Garcia A, Alonso Frech F, Alvarez Lopez M, et al. Efficacy of long-term continuous subcutaneous apomorphine infusion in advanced Parkinson's disease with motor fluctuations: a multicenter study. Mov Disord 2008; 23: 1130-6. [CrossRef]

28. Boyle A, Ondo W. Role of apomorphine in the treatment of Parkinson's disease. CNS Drugs 2015; 29: 83-9. [CrossRef]

29. Pogarell O, Gasser T, van Hilten JJ, Spieker S, Pollentier S, Meier D, Oertel WH. Pramipexole in patients with Parkinson's disease and marked drug resistant tremor: a randomised, double blind, placebo controlled multicentre study. J Neurol Neurosurg Psychiatry 2002; 72: 713-20. [CrossRef]

30. Antonini A, Barone P, Ceravolo R, Fabbrini G, Tinazzi M, Abbruzzese G. Role of pramipexole in the management of Parkinson's disease. CNS Drugs 2010; 24: 829-41. [CrossRef]

31. Leentjens AF, Koester J, Fruh B, Shephard DT, Barone P, Houben JJ. The effect of pramipexole on mood and motivational symptoms in Parkinson's disease: a meta-analysis of placebo-controlled studies. Clin Ther 2009; 31: 89-98. [CrossRef]

32. Antonini A, Tolosa E, Mizuno Y, Yamamoto M, Poewe WH. A reassessment of risks and benefits of dopamine agonists in Parkinson's disease. Lancet Neurol 2009; 8: 929-37. [CrossRef]

33. Faulkner MA. Safety overview of FDA-approved medications for the treatment of the motor symptoms of Parkinson's disease. Expert Opin Drug Saf 2014; 13: 1055-69. [CrossRef]

34. Samanta J, Hauser RA. Duodenal levodopa infusion for the treatment of Parkinson's disease. Expert Opin Pharmacother 2007; 8: 657-64. [CrossRef]

35. Jenner P. Avoidance of dyskinesia: preclinical evidence for continuous dopaminergic stimulation. Neurology 2004; 62: S47-55. [CrossRef]

36. Nyholm D, Nilsson Remahl AI, Dizdar N, Constantinescu R, Holmberg $\mathrm{B}$, Jansson R, et al. Duodenal levodopa infusion monotherapy vs oral polypharmacy in advanced Parkinson disease. Neurology 2005; 64: 216-23. [CrossRef]

37. Olanow W, Schapira AH, Rascol O. Continuous dopamine-receptor stimulation in early Parkinson's disease. Trends Neurosci 2000; 23 : S117-26. [CrossRef]

38. Rodnitzky RL, Narayanan NS. Amantadine's role in the treatment of levodopa-induced dyskinesia. Neurology 2014; 82: 288-9. [CrossRef]

39. Jenner P. Molecular mechanisms of L-DOPA-induced dyskinesia. Nat Rev Neurosci 2008; 9: 665-77. [CrossRef]

40. Pirtosek Z. 'Bad guys' among the antiparkinsonian drugs. Psychiatr Danub 2009; 21: 114-8.

41. Castrioto A, Lozano AM, Poon YY, Lang AE, Fallis M, Moro E. Tenyear outcome of subthalamic stimulation in Parkinson disease: a blinded evaluation. Arch Neurol 2011; 68: 1550-6. [CrossRef] 